\title{
Human Osteochondral Explants: Reliable Biomimetic Models to Investigate Disease Mechanisms and Develop Personalized Treatments for Osteoarthritis
}

\author{
Evelyn Houtman (D) - Marcella van Hoolwerff (D) · Nico Lakenberg • \\ Eka H. D. Suchiman · Enrike van der Linden-van der Zwaag • \\ Rob G. H. H. Nelissen (D) · Yolande F. M. Ramos (D) · Ingrid Meulenbelt (D)
}

Received: December 7, 2020 / Accepted: January 30, 2021 / Published online: February 20, 2021

(c) The Author(s) 2021

\section{ABSTRACT}

Introduction: Likely due to ignored heterogeneity in disease pathophysiology, osteoarthritis (OA) has become the most common disabling joint disease, without effective disease-modifying treatment causing a large social and economic burden. In this study we set out to explore responses of aged human osteochondral explants upon different OA-related perturbing triggers (inflammation, hypertrophy and mechanical stress) for future tailored biomimetic human models.

Methods: Human osteochondral explants were treated with IL-1 $\beta(10 \mathrm{ng} / \mathrm{ml})$ or triiodothyronine $(\mathrm{T} 3 ; 10 \mathrm{nM})$ or received $65 \%$ strains of mechanical stress (65\% MS). Changes in chondrocyte signalling were determined by

Supplementary Information The online version contains supplementary material available at https:// doi.org/10.1007/s40744-021-00287-y.

E. Houtman · M. van Hoolwerff · N. Lakenberg

E. H. D. Suchiman . Y. F. M. Ramos .

I. Meulenbelt $(\square)$

Molecular Epidemiology, Department of Biomedical

Data Sciences, Leiden University Medical Center,

Leiden, The Netherlands

e-mail: i.meulenbelt@lumc.nl

E. van der Linden-van der Zwaag

R. G. H. H. Nelissen

Department of Orthopaedics, Leiden University

Medical Center, Leiden, The Netherlands expression levels of nine genes involved in catabolism, anabolism and hypertrophy. Breakdown of cartilage was measured by sulphated glycosaminoglycans (sGAGs) release, scoring histological changes (Mankin score) and mechanical properties of cartilage.

Results: All three perturbations (IL-1 $\beta, \mathrm{T} 3$ and $65 \% \mathrm{MS}$ ) resulted in upregulation of the catabolic genes MMP13 and EPAS1. IL-1 $\beta$ abolished COL2A1 and ACAN gene expression and increased cartilage degeneration, reflected by increased Mankin scores and sGAGs released. Treatment with T3 resulted in a high and significant upregulation of the hypertrophic markers COL1A1, COL1OA1 and ALPL. However, 65\% MS increased sGAG release and detrimentally altered mechanical properties of cartilage.

Conclusion: We present consistent and specific output on three different triggers of OA. Perturbation with the pro-inflammatory IL-1 $\beta$ mainly induced catabolic chondrocyte signalling and cartilage breakdown, while T3 initiated expression of hypertrophic and mineralization markers. Mechanical stress at a strain of $65 \%$ induced catabolic chondrocyte signalling and changed cartilage matrix integrity. The major strength of our ex vivo models was that they considered aged, preserved, human cartilage of a heterogeneous OA patient population. As a result, the explants may reflect a reliable biomimetic model prone to OA onset allowing for development of different treatment modalities. 
Keywords: Cartilage; Hypertrophy; Inflammation; Human biomimetic model; Mechanical stress; Osteoarthritis; Osteochondral explants

\section{Key Summary Points}

Likely due to ignored heterogeneity in disease pathophysiology, osteoarthritis has become the most common disabling joint disease, without effective diseasemodifying treatment causing high social and economic burden

Advancements in clinical development are hampered by a lack of tailored biomimetic human preclinical models mimicking different aspects of osteoarthritis pathophysiology

Is it possible to set up personalized human preclinical models of osteoarthritis that mimic different aspects of the osteoarthritic pathophysiology such as inflammation, hypertrophy or mechanical stress?

An inflammatory OA trigger (IL-1 $\beta$ ) mainly induced catabolic chondrocyte signalling and cartilage breakdown, mechanical stress at a strain of $65 \%$ induced moderate catabolic chondrocyte signalling and changed the cartilage matrix integrity, while T3 initiated expression of hypertrophic and mineralization markers

This demonstrates that it is possible to set up personalized human OA disease models reflecting different relevant aspects (inflammation, hypertrophy and mechanical stress) of osteoarthritic pathophysiology readily applicable in future drug testing

\section{DIGITAL FEATURES}

This article is published with digital features, including, e.g., a summary slide, to facilitate understanding of the article. To view digital features for this article go to https://doi.org/10. 6084/m9.figshare.13664675.

\section{INTRODUCTION}

Osteoarthritis (OA) is the most prevalent chronic age-related joint disease, causing pain and disability [1]. Likely due to ignored heterogeneity in disease pathophysiology, osteoarthritis has become the most common disabling joint disease, without effective disease-modifying OA drugs (DMOADs) causing great social and economic burdens. As a result, OA significantly decreases quality of life while increasing absenteeism from work and healthcare costs [2].

The OA disease process itself is characterized by unfavourable dynamic regulation of chondrocytes upon environmental perturbations such as age or mechanical stress, likely in interaction with genetic variants that cause subtle changes in expression of OA risk genes. The OA pathophysiological process itself has been linked to enhanced metabolic activity of articular chondrocytes, resembling growth plate chondrocytes undergoing endochondral ossification [3]. OA chondrocytes enter a cascade of proliferation and hypertrophic differentiation, accompanied by expression of genes such as alkaline phosphatase (ALPL), collagen $\mathrm{X}$ (COL10A1) and matrix metallopeptidase 13 (MMP13), resulting in apoptotic death and mineralization of cartilage [4-8]. Other hallmarks of the OA disease pathophysiology include new bone formation at the joint margins, limited inflammation and changes in subchondral bone structure. Together, these OA risk factors impose a persistent, yet variable, negative influence on joint tissue homeostasis throughout life, inevitably leading to progressive joint tissue destruction with age [9].

To address shortcomings of translational research and the challenges of translating data from in vitro models and a preclinical animal 
model to humans and increase efficiency of effective and safe drug development, while being compliant with the guiding principles of reduction, refinement and replacement of animal experiments, validated human models mimicking the different aspects of OA pathophysiology are required. Nonetheless, preclinical models thus far are limited to post-traumatic animal models or analyses of cell signalling in $2 \mathrm{D}$ and $3 \mathrm{D}$ in vitro cultures of neo-cartilage derived from human articular chondrocytes or stem cells. However, none of these models reliably recapitulate the osteochondral compartment, let alone faithfully representing agerelated joint tissues prone to enter the OA process upon disease-initiating cues.

Osteochondral explant-based models allow investigation of both bone and cartilage compartments at the same time. The major advantage of such a model is that the cell response can be determined in their natural environment and they are relatively simple and easy to produce. Most commonly used explant-based models thus far were of bovine origin and applied a super-physiological perturbing factor of either a fierce inflammatory cytokines treatment [10-12] or cartilage loading [13-15]. Next to inflammation and mechanical loading, recapitulation of endochondral ossification and thereby hypertrophy is also thought to be one of the major mechanisms driving the processes in OA [16].

The aim of the current study is to explore and compare responses of aged human osteochondral explants triggered by three different physiological perturbing cues: inflammation (IL-1 $\beta)$ [17, 18], hypertrophy [triiodothyronine (T3)] $[19,20]$ and mechanical stress (65\% strain) [21]. We determined different output measures related to catabolic, anabolic and hypertrophic chondrocyte signalling, sGAG released into the media, cartilage structure by histology and changes in mechanical properties. The presented models enable in-depth studies on how such cues interfering with homeostasis of aged cartilage contribute to human OA onset. They also allow for personalized testing of new treatment regimes in a validated human model including interaction of joint tissues and essential environmental cues.

\section{METHODS}

\section{Osteochondral Explant Cultures}

Osteochondral explants were obtained from joints included in the Research in Articular Osteoarthritis Cartilage (RAAK) study. The RAAK study was approved by the medical ethics committee of the Leiden University Medical Center (P08.239/P19.013) and informed consent was obtained from subjects. Osteochondral explants were harvested from the macroscopically preserved area of knee joints of human OA patients within $2 \mathrm{~h}$ of joint replacement surgery. Donor characteristics are summarized in Table S1. Osteochondral explants containing both cartilage and bone ( $8 \mathrm{~mm}$ diameter) were washed in sterile PBS and equilibrated in serumfree chondrogenic differentiation medium [DMEM (high glucose; Gibco, Bleiswijk), supplemented with ascorbic acid $(50 \mu \mathrm{g} / \mathrm{ml}$; SigmaAldrich; Zwijndrecht, The Netherlands), L-proline $(40 \mu \mathrm{g} / \mathrm{ml}$; Sigma-Aldrich), sodium pyruvate $\quad(100 \mu \mathrm{g} / \mathrm{ml} ; \quad$ Sigma-Aldrich $)$, dexamethasone $(0.1 \mu \mathrm{m} ; \quad$ Sigma-Aldrich $)$, ITS + and antibiotics $(100 \mathrm{U} / \mathrm{ml}$ penicillin; $100 \mu \mathrm{g} / \mathrm{ml}$ streptomycin; Gibco)] in a $5 \%(\mathrm{v} / \mathrm{v})$ $\mathrm{CO}_{2}$ incubator at $37^{\circ} \mathrm{C}$.

\section{Application of Physiologically Relevant Cues}

Three days after extraction, explant tissue was treated with IL-1 $\beta(10 \mathrm{ng} / \mathrm{ml})$ or triiodothyronine $(\mathrm{T} 3,10 \mathrm{nM})$. After 6 days, dynamic unconfined compression was applied to explant tissue using the Mach-1 mechanical testing system on 4 subsequent days (Biomomentum Inc., Laval, QC, Canada). Physiological loading at a strain of $30 \%$ or $65 \%$ was applied to explants at a frequency of $1 \mathrm{~Hz}$. The thickness of the cartilage was measured prior to loading and used to determine the strain for each explant. Media of explants was refreshed every 3-4 days. To investigate lasting effects of treatment, explants were harvested 3 days after the last treatment. Cartilage and bone were separated using a scalpel, snap-frozen in liquid nitrogen and stored at $-80^{\circ} \mathrm{C}$ for RNA isolation. 


\section{RNA Isolation, Reverse Transcription and Quantitative Real-Time PCR}

RNA was extracted by pulverizing the tissue using a Mixer mill 200 (Retch, Germany) and homogenizing in TRIzol reagent (Invitrogen, San Diego, CA). RNA was extracted with chloroform, precipitated with ethanol and purified using the RNeasy Mini Kit (Qiagen, GmbH, Hilden, Germany). Genomic DNA was removed by DNase (Qiagen, GmbH, Hilden, Germany) digestion, and the quantity of RNA was assessed using a Nanodrop spectrophotometer (Thermo Fischer Scientific Inc., Wilmington, DE, USA). Synthesis of cDNA was performed using $200 \mathrm{ng}$ of total mRNA with the First Strand cDNA Synthesis Kit (Roche Applied Science, Almere, The Netherlands) according to the manufacturer's protocol. Gene expression was determined with the Roche Lightcycler 480 II (Roche Applied Science) using Fast Start Sybr Green Master mix (Roche Applied Science). Primer sequences are listed in Table S2.

\section{Sulphated Glycosaminoglycan (sGAGs) Measurement}

Sulphated glycosaminoglycan (sGAG) concentration was measured with the photometric 1.9 dimethylene blue (DMMB; Sigma-Aldrich) dye method [22]. Shark chondroitin sulphate (Sigma-Aldrich) was used as reference standard. To measure concentrations, absorbance at 525 and 595 was measured in a microplate reader (Synergy HT; BioTek, Winooski, VT, USA).

\section{Histology}

Osteochondral explants were fixed in 4\% formaldehyde and decalcified using EDTA $(12.5 \%$, pH $=7.4)$, dehydrated with an automated tissue processing apparatus and embedded in paraffin. Tissue sections of $5 \mu \mathrm{m}$ were stained with haematoxylin and eosin (H\&E) or toluidine blue (Sigma-Aldrich) and mounted with Pertex (Sigma-Aldrich). Quantification of OA-related cartilage damage was scored according to Mankin et al. [23].

\section{Mechanical Properties}

The fibril-network-reinforced biphasic model of cartilage in unconfined compression was used to measure the mechanical properties of explants [24]. After a $10 \%$ precompression five subsequent ramps of $2 \%$ were performed and each ramp was allowed to continue until the relaxation rate was $<0.05 \mathrm{~N} / \mathrm{min}$. The tensile stiffness of the fibril network $\left(E_{f}\right)$, equilibrium modulus $\left(E_{m}\right)$ and hydraulic permeability $(k)$ were determined using MACH-1 software (Biomomentum Inc., Laval, QC, Canada).

\section{Statistical Analysis}

Statistics were performed for all data in IBM SPSS statistics 23. In the absence of perfect pairs, the significance of mean difference in gene expression between controls and treated explants was estimated by the generalized estimating equation (GEE) with robust variance estimators to account for donor effects. RT-PCR data were normalized using the housekeeping gene SDHA. We used SDHA, as this gene was previously identified as a stable housekeeping gene in cartilage and particularly not responsive to mechanical stress $[25,26]$. Fold changes were calculated according to the $2^{-\Delta \Delta C T}$ method. Significance was declared at $P<0.05$.

\section{RESULTS}

\section{Baseline Characteristics of Donors of the Osteochondral Explants}

As shown in Table S1, age and BMI are comparable across donors in the three different perturbations applied: IL-1 $\beta$, T3 and 65\% mechanical stress $(65 \% \mathrm{MS})$. Of note, IL- $1 \beta$ was applied by chance in explants from females only. Prior to applying our models we explored effects of $30 \%$ stress to osteochondral explants compared to controls and IL-1 $\beta$ or T3 treatment. As shown in Figs. S1 and S2 and Tables S2 and S3, 30\% mechanical stress as compared to controls had no significant effect on gene expression levels, Mankin score or sGAG 
concentrations (data not published). To enlarge our sample sizes for the remaining analysis, the $30 \%$ stressed control samples were pooled with controls of the IL-1 $\beta$ and T3 treated groups.

\section{Changes in Chondrocyte Signaling Across the Three Models}

As shown in Table 1, applying the three different perturbations (IL-1 $\beta$, T3 and 65\% MS) resulted in significant upregulation of the catabolic genes MMP13 and EPAS1 as compared to controls (Fig. 1). Upregulation of MMP13 (Fig. 1c) was modest in response to $\mathrm{T} 3(\mathrm{FC}=3.7$; $P=3.0 \times 10^{-3}$ ) relative to that with IL-1 $\beta$ $\left(\mathrm{FC}=12.7 ; P=3.6 \times 10^{-2}\right.$, Fig. $\left.1 \mathrm{a}\right)$ and $65 \% \mathrm{MS}$ (FC $=10.3 ; P=1.4 \times 10^{-2}$, Fig. 1b). Upregulation of EPAS1 was highly significant in response to IL- $1 \beta, 65 \%$ MS and T3 treatment $(\mathrm{FC}=4.6$; $P=3.6 \times 10^{-2}, \quad \mathrm{FC}=1.8 ; \quad P=1.8 \times 10^{-20}$ and FC $=1.8 ; \quad P=1.0 \times 10^{-3}$, respectively Fig. 1$)$. Notable is the observed absence in expression changes of the aggrecanase ADAMTS5 in all three perturbations (Table 1; Fig. 1).

Regarding the matrix genes known to be responsible for a substantial part of the matrix deposition, we showed that COL2A1 and ACAN expression was almost absent in the IL- $1 \beta$ treated osteochondral explants with a $\mathrm{FC}=0.01$; $P=2.6 \times 10^{-12}$ and FC $=0.03 ; P=1.1 \times 10^{-19}$, respectively (Fig. 2a). Sixty-five percent MS resulted in a slight, non-significant downregulation of COL2A1 (FC $=0.9 ; \quad P=8.7 \times 10^{-2}$, Fig. $2 \mathrm{~b}$ ) and no changes in $A C A N$ expression. In contrast, treatment with $\mathrm{T} 3$ resulted in a highly significant upregulation of COL2A1 $(\mathrm{FC}=3.5$; $P=2.4 \times 10^{-10}$, Fig. 2c).

As shown in Table 1 and Fig. 3c, treatment with $\mathrm{T} 3$ resulted in a high and significant upregulation of the hypertrophic markers COL1A1 $\left(\mathrm{FC}=144.7 ; P=0.3 \times 10^{-3}\right)$, COL1OA1 $\left(\mathrm{FC}=5.0 ; P=6 \times 10^{-3}\right)$ and $A L P L(\mathrm{FC}=665.8$; $P=7.4 \times 10^{-9}$ ) compared to controls.

\section{sGAG Release Following Cartilage Perturbation}

To explore breakdown of cartilage, we measured sGAG released by the cartilage in the media on day 3, day 6, day 10 and day 13. In Fig. S3 we outlined the accumulation of sGAG release from explants to the medium between day 3 and 6 , and in Fig. 4 between day 6 and 13, representing early and late release, respectively. IL-1 $\beta$ significantly increased release of sGAG into the medium at day 6 relative to day 3 (19\% increase from 194.4 to $426.1 \mu \mathrm{g} / \mathrm{ml}$ versus 194.5 to $366.0 \mu \mathrm{g} / \mathrm{ml} ; P=0.03$; Fig. S3A) compared to controls. This increased release was prolonged at a significant and higher rate at day $10(52 \%$ increase of $51.4 \mu \mathrm{g} / \mathrm{ml}$ versus $77.8 \mu \mathrm{g} / \mathrm{ml}$; $P=6.0 \times 10^{-3} ; \quad$ Fig. $\left.4 \mathrm{a}\right)$ and day $13(99 \%$ increase of $59.8 \mu \mathrm{g} / \mathrm{ml}$ versus $118.9 \mu \mathrm{g} / \mathrm{ml}$; $P=4.9 \times 10^{-8} ; \quad$ Fig. $\left.4 a\right)$. Although some increased sGAG release after $65 \% \mathrm{MS}$ and T3 treatment was observed at day 13 , there was no significant difference compared to controls (30\% increase of $32.3 \mu \mathrm{g} / \mathrm{ml}$ versus $42.6 \mu \mathrm{g} / \mathrm{ml}$; $P=0.09$ and $4 \%$ increase of $28.8 \mu \mathrm{g} / \mathrm{ml}$ versus $30.0 \mu \mathrm{g} / \mathrm{ml} ; P=0.8$, respectively; Fig. $4 \mathrm{~b}, \mathrm{c})$.

\section{Changes of the Cartilage Integrity Observed by Histology}

To evaluate the microscopic changes in the cartilage tissue quality, we applied Mankin scoring to control and perturbed explants at day 13. As shown in Fig. 5 a and Table 1, IL- $1 \beta$ significantly increased the overall Mankin score (2.7 vs. $4.1 ; P=6.3 \times 10^{-4}$ ) compared to controls. Upon investigating the different components of the Mankin score separately (cartilage structure, cellularity, loss of sGAG and integrity of tidemark), it appeared that the difference observed for IL-1 $\beta$ treatment was mainly driven by differences in cartilage structure such as fibrillations and fissures and loss of sGAGs by toluidine blue staining $(1.2$ vs. 2.0, $P=8.1 \times 10^{-3}$ and 0.4 vs. $1.3, P=3.2 \times 10^{-3}$, respectively, Table 1; Figs. 5d, S4). Although we observed visible fissures and surface deformations only in explants upon 65\% MS (Fig. S5), suggesting cartilage breakdown, this was not reflected by a significant change in the Mankin scores (Table 1; Fig. 5c). 
Table 1 Summary of the different outcome parameters in response to perturbation with IL-1 $\beta$, T3 or $65 \%$ mechanical stress (MS)

\begin{tabular}{|c|c|c|c|c|c|c|}
\hline \multirow[t]{2}{*}{ Outcome measure } & \multicolumn{2}{|l|}{ IL-1及 } & \multicolumn{2}{|l|}{ T3 } & \multicolumn{2}{|c|}{$65 \% \mathrm{MS}$} \\
\hline & $\overline{\text { FC }^{*}}$ & $P$ value ${ }^{\$}$ & $\overline{\text { FC }^{*}}$ & $P$ value ${ }^{\$}$ & $\overline{\text { FC }^{*}}$ & $P$ value ${ }^{\$}$ \\
\hline \multicolumn{7}{|l|}{ Gene expression } \\
\hline \multicolumn{7}{|l|}{ Catabolism } \\
\hline$M M P 13$ & 12.66 & $3.60 \times 10^{-2}$ & 3.74 & $3.00 \times 10^{-3}$ & 10.27 & $1.40 \times 10^{-2}$ \\
\hline ADAMTS5 & 1.26 & NS & 0.74 & NS & 1.04 & NS \\
\hline$E P A S 1$ & 4.56 & $3.60 \times 10^{-2}$ & 1.83 & $1.00 \times 10^{-3}$ & 1.77 & $1.80 \times 10^{-20}$ \\
\hline \multicolumn{7}{|l|}{ Anabolism } \\
\hline$A C A N$ & 0.03 & $1.08 \times 10^{-19}$ & 0.97 & NS & 1.18 & NS \\
\hline$C O L 2 A 1$ & 0.01 & $2.56 \times 10^{-12}$ & 3.45 & $2.40 \times 10^{-10}$ & 0.91 & NS \\
\hline \multicolumn{7}{|l|}{ Hyperthrophy } \\
\hline$C O L 1 A 1$ & 0.22 & NS & 144.68 & $3.00 \times 10^{-3}$ & 1.91 & NS \\
\hline COL10A1 & 0.23 & NS & 5.04 & $6.11 \times 10^{-3}$ & 3.82 & NS \\
\hline$A L P$ & 2.80 & NS & 665.82 & $7.42 \times 10^{-9}$ & 2.73 & NS \\
\hline$R U N X 2$ & 0.68 & $5.00 \times 10^{-2}$ & 1.18 & NS & 1.78 & NS \\
\hline \multirow[t]{2}{*}{ Outcome measure } & \multicolumn{2}{|l|}{ IL-1及 } & \multicolumn{2}{|l|}{ T3 } & \multicolumn{2}{|c|}{$65 \% \mathrm{MS}$} \\
\hline & Beta $^{* *}$ & $P$ value $\$$ & Beta $^{* *}$ & $P$ value ${ }^{\$}$ & Beta $^{* *}$ & $P$ value $\$$ \\
\hline \multicolumn{7}{|l|}{ Histology } \\
\hline \multicolumn{7}{|l|}{ Mankin score } \\
\hline Cartilage structure & 0.83 & $8.12 \times 10^{-3}$ & 0.45 & NS & 0.20 & NS \\
\hline Cellularity & 0.36 & NS & 0.09 & NS & 0.04 & NS \\
\hline Toluidine blue & 0.79 & $3.15 \times 10^{-3}$ & -0.07 & NS & 0.16 & NS \\
\hline Tidemark integrity & -0.02 & NS & 0.06 & NS & 0.10 & NS \\
\hline Mankin score & 1.95 & $5.47 \times 10^{-4}$ & 0.53 & NS & 0.50 & NS \\
\hline \multicolumn{7}{|l|}{ sGAG } \\
\hline \multicolumn{7}{|l|}{ Medium } \\
\hline Day 4 & -0.10 & NS & 23.19 & NS & 10.21 & NS \\
\hline Day 6 & 60.51 & $7.87 \times 10^{-2}$ & -1.95 & NS & 1.56 & NS \\
\hline Day 10 & 26.48 & $6.01 \times 10^{-3}$ & 2.59 & NS & 7.85 & NS \\
\hline Day 13 & 59.09 & $4.85 \times 10^{-8}$ & 1.27 & NS & 10.31 & NS \\
\hline \multicolumn{7}{|l|}{ Cartilage tissue } \\
\hline Day 13 & -1.95 & NS & 0.04 & NS & 2.72 & NS \\
\hline
\end{tabular}


Table 1 continued

\begin{tabular}{|c|c|c|c|c|c|c|}
\hline \multirow[t]{2}{*}{ Outcome measure } & \multicolumn{2}{|l|}{ IL-1及 } & \multicolumn{2}{|l|}{ T3 } & \multicolumn{2}{|c|}{$65 \% \mathrm{MS}$} \\
\hline & Beta $^{* *}$ & $P$ value ${ }^{\mathrm{s}}$ & Beta $^{* *}$ & $P$ value ${ }^{\mathrm{s}}$ & Beta $^{* *}$ & $P$ value $\$$ \\
\hline \multicolumn{7}{|c|}{ Mechanical properties } \\
\hline \multicolumn{7}{|c|}{ Fibril network modulus } \\
\hline Day 6 & -0.11 & NS & 0.01 & NS & -0.07 & NS \\
\hline Day 10 & -0.04 & NS & 0.21 & NS & -0.48 & $2.57 \times 10^{-2}$ \\
\hline Day 13 & -0.03 & NS & 0.19 & NS & -0.35 & NS \\
\hline \multicolumn{7}{|c|}{ Equilibrium modulus } \\
\hline Day 6 & -0.02 & NS & 0.05 & NS & -0.02 & NS \\
\hline Day 10 & -0.02 & NS & 0.02 & NS & -0.10 & $2.68 \times 10^{-2}$ \\
\hline Day 13 & -0.01 & NS & 0.08 & NS & -0.07 & NS \\
\hline \multicolumn{7}{|l|}{ Permeability } \\
\hline Day 6 & 6.44 & NS & 0.93 & NS & 0.84 & NS \\
\hline Day 10 & 3.62 & NS & 4.17 & NS & 2.46 & NS \\
\hline Day 13 & 0.71 & NS & -2.62 & NS & 1.45 & NS \\
\hline
\end{tabular}

Given in this table are the different parameters measured: gene expression, histology, sGAG concentration and mechanical properties

$M S$ mechanical stress, $N S$ not significant, $s G A G$ sulphated glycosaminoglycans

${ }^{*} \mathrm{FC}$ is determined by the $2^{-\Delta \Delta \mathrm{CT}}$ method and compared to its respective controls

${ }^{* *}$ Beta is determined by the GEE during the modelling and represents the difference between the perturbation and control groups

$\$$ Significance of mean difference in gene expression between controls and treated explants was estimated by the generalized estimating equation (GEE) with robust variance estimators to account for donor effects

\section{Changes in Mechanical Properties of the Cartilage}

To explore the mechanical properties of cartilage in response to the treatments, we determined three different aspects of mechanical properties available at the MACH1 apparatus on day 6 , day 10 and day 13 . These aspects were the fibril network modules $\left(E_{f}\right)$, equilibrium modulus $\left(E_{m}\right)$ and hydraulic permeability $(k)$, reflecting the tensile stiffness, elastic coefficient (Young's modulus) and water retention, respectively. As shown in Fig. 6, 65\% MS significantly negatively affected the fibril network modulus $\left(0.9\right.$ vs. $0.5 \mathrm{MPa} ; \quad P=2.6 \times 10^{-2}$;
Fig. 6a) and equilibrium modulus $(0.2$ vs. $0.1 \mathrm{MPa} ; P=2.7 \times 10^{-2}$; Fig. $6 \mathrm{~b}$ ) at day 10 while simultaneously, though not significantly, increasing the hydraulic permeability of the cartilage by $300 \%$ (control vs. $65 \%$ MS; 0.8 vs. $3.2 \mathrm{~mm}^{2} / \mathrm{MPa} \mathrm{s}$; $=0.2$; Fig. $6 \mathrm{c}$ ). No significant differences in mechanical properties were detected for IL-1 $\beta$ and T3 treated osteochondral explants.

\section{DISCUSSION}

We present human ex vivo osteochondral explants as a model system to study OA-related 
A

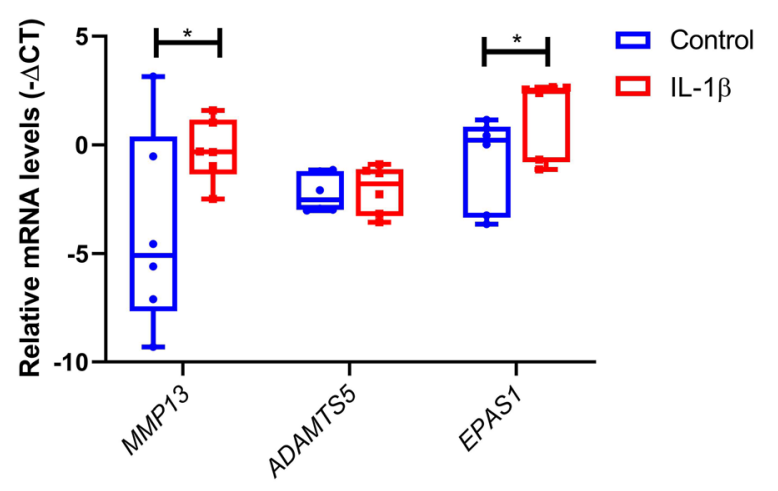

C

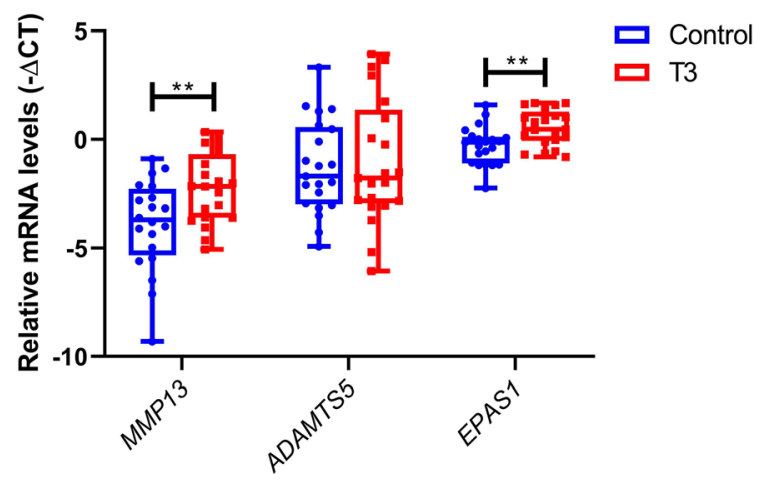

Fig. 1 Gene expression of catabolic markers after treatment with IL-1 $\beta$, mechanical stress (MS) or T3. RT-PCR analysis of MMP13, ADAMTS5 and EPAS1 after a IL-1 $\beta$ $(10 \mathrm{ng} / \mathrm{ml} ; n=6), \mathbf{b} 65 \%$ MS $(n=19-23)$ or c T3 $(10 \mathrm{nM} ; n=21)$ treatment. Data are presented in a boxplot depicting the median, lower and upper quartiles

changes after three known pathophysiological perturbations. We applied IL-1 $\beta$, T3 and 65\% MS as relevant perturbing factors and studied a variety of output measures including chondrocyte signalling, cartilage structure and breakdown, and mechanical properties. Our data provide a relevant personalized human model for research on OA, which can be used for target identification and/or drug efficacy testing. The biomimetic model also complies with the guiding principles of reduction, refinement and replacement of animal experiments.

An increased catabolic response was measured after perturbation in all three models. The highest increase in MMP13 gene expression was measured in response to IL-1 $\beta(\mathrm{FC}=12.7)$, followed by mechanical stress $(\mathrm{FC}=10.3)$, while
B

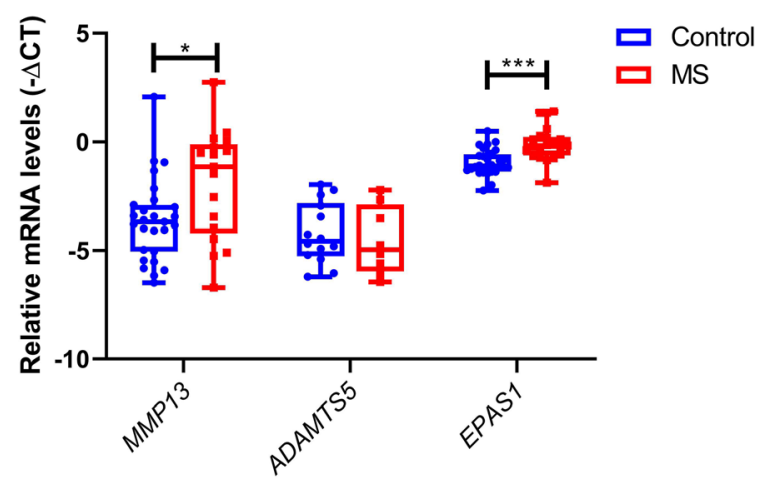

and each dot represents a single explant. $P$ values of mean differences in gene expression between controls and treated explants were estimated by generalized estimating equations (GEE) with robust variance estimators to account for donor effects. ${ }^{*} P<0.05,{ }^{* *} P<0.01,{ }^{* *} P<0.001$

the lowest increase was observed after T3 treatment $(F C=3.7)$. Strikingly, none of the treatments induced a significant increase in ADAMTS5 gene expression. Moreover, we measured a greatly significant increase of EPAS1 in all three OA models, indicating its sensitivity to a perturbed cartilage homeostasis. The EPAS1 gene encodes HIF- $2 \alpha$ and its role in the onset of $\mathrm{OA}$ in humans is unclear as both increased $[27,28]$ and decreased [29] expression has been reported in human OA cartilage. Functionally, HIF- $2 \alpha$ has been shown to regulate endochondral ossification in mouse studies by inducing expression of genes mediating chondrocyte hypertrophy (Col10a1), matrix degradation (Mmp13) and vascular invasion (Vegfa) [27]. 


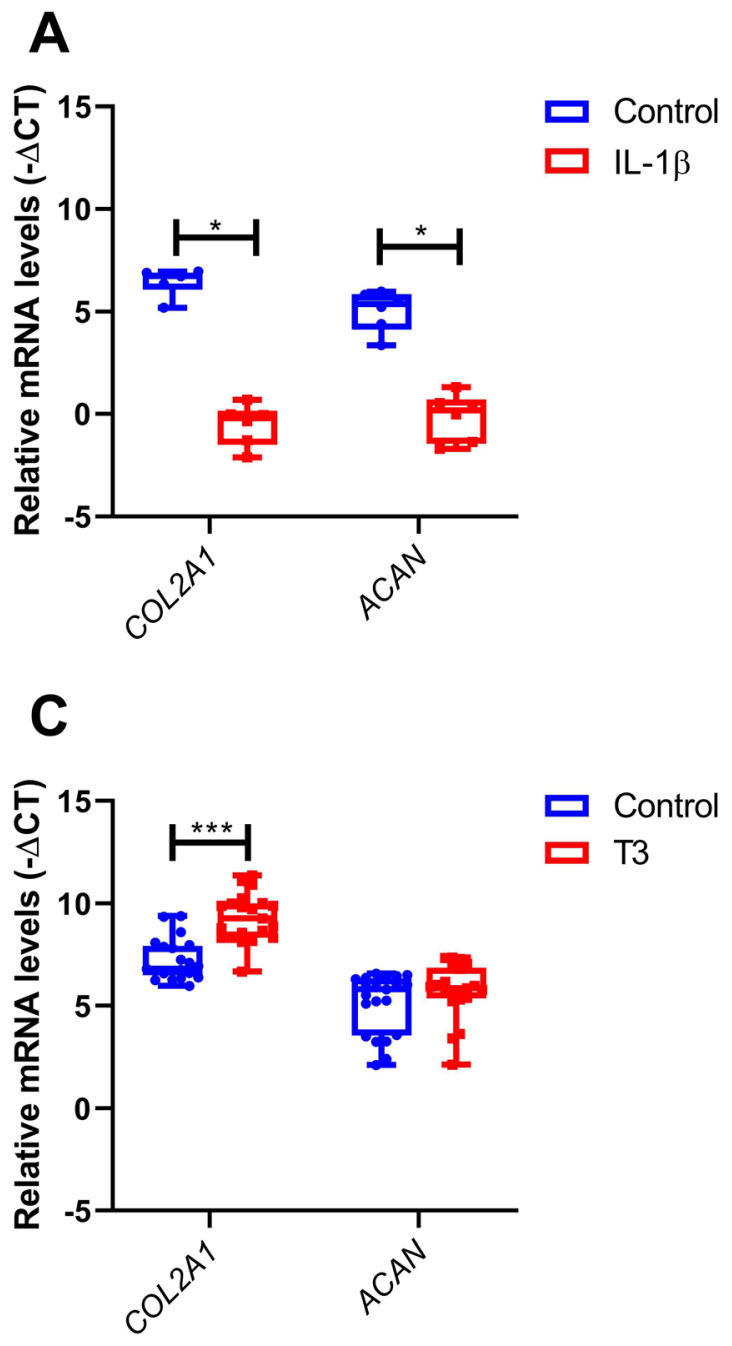

Fig. 2 Gene expression of anabolic markers after treatment with IL-1 $\beta$, mechanical stress (MS) or T3. RT-PCR analysis of $C O L 2 A 1$ and $A C A N$ after a IL- $1 \beta(10 \mathrm{ng} / \mathrm{ml}$; $n=6)$, b $65 \%$ MS $(n=19-23)$ or c T3 (10 nM; $n=21)$ treatment. Data are presented in a boxplot depicting the median, lower and upper quartiles and each dot represents

We observed that the three different perturbations were diverse in the other outcome measures. The most severe cartilage breakdown was observed after treatment with the pro-inflammatory IL- $1 \beta$ and this breakdown was also characterized by an increased chondrocyte cell signalling of catabolism (MMP13 and EPAS1, Fig. 1a) and abolishment of anabolic cell signalling ( $A C A N$ and COL2A1, Fig. 2a). Gene expression of COL2A1 and ACAN was downregulated by IL-1 $\beta \quad 100$ and 33 times,

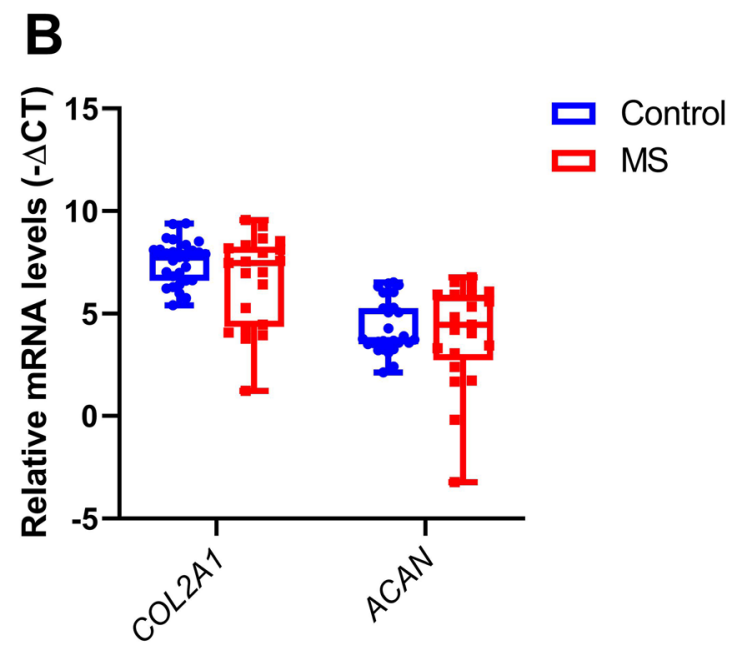

a single explant. $P$ values of mean differences in gene expression between controls and treated explants were estimated by generalized estimating equations (GEE) with robust variance estimators to account for donor effects. ${ }^{*} P<0.05,{ }^{* *} P<0.01,{ }^{* * *} P<0.001$

respectively, suggesting a very low expression of these normally highly expressed cartilage genes. This shift in chondrocyte signalling towards catabolism is confirmed by cartilage breakdown, as measured by a stark 99\% increased release of sGAG from cartilage (Fig. 4a) and by a 1.95 times increased Makin score (Fig. 5a). Upon investigation of the different subcategories of the Mankin scoring, we observed that IL-1 $\beta$ greatly reduced cartilage quality as measured by a 3.2 times reduction of staining for sGAG 
A

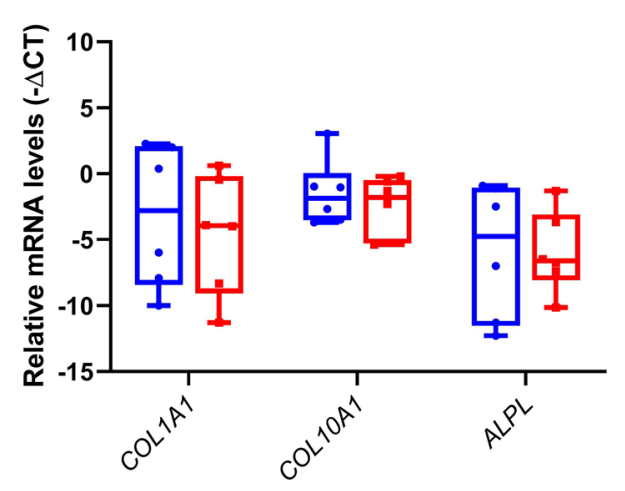

C

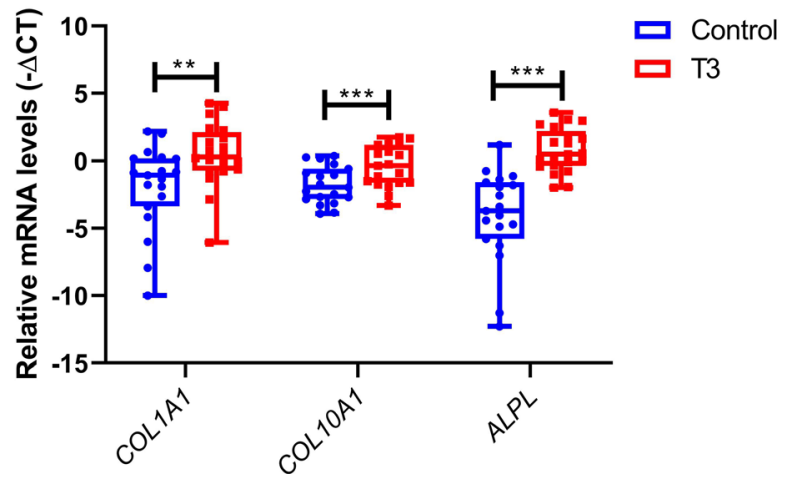

Fig. 3 Gene expression of hypertrophic and mineralization markers after treatment with IL-1 $\beta$, mechanical stress (MS) or T3. RT-PCR analysis of COL1A1, COL10A1 and $A L P L$ after a IL- $1 \beta(10 \mathrm{ng} / \mathrm{ml} ; n=6)$, b $65 \% \mathrm{MS}$ $(n=19-23)$ or c T3 (10 nM; $n=21)$ treatment. Data are presented in a boxplot depicting the median, lower and
B

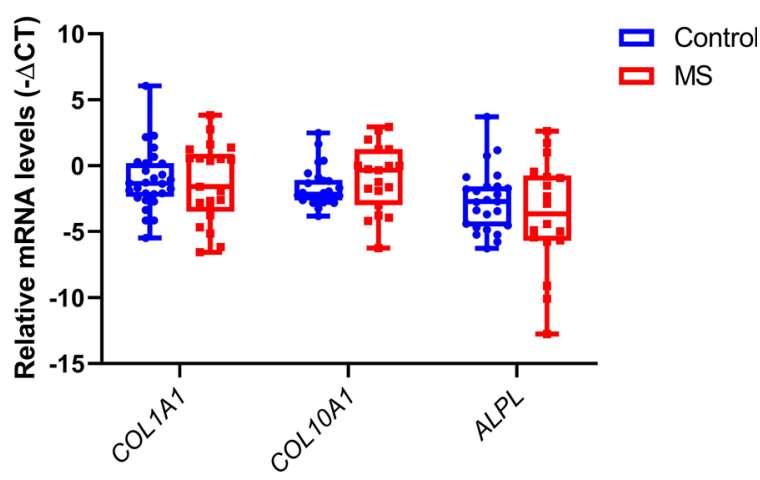

upper quartiles and each dot represents a single explant. $P$ values of mean differences in gene expression between controls and treated explants were estimated by generalized estimating equations (GEE) with robust variance estimators to account for donor effects. ${ }^{*} P<0.05$, ${ }^{* *} P<0.01$, ${ }^{* * *} P<0.001$
A

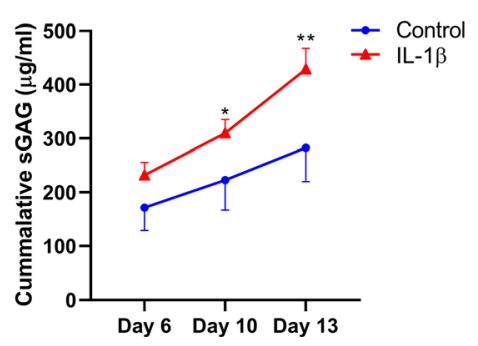

Fig. 4 sGAG concentration in the media of osteochondral explants. Cummulative sGAG release $(\mu \mathrm{g} / \mathrm{ml})$ in media of osteochondral explants in presence of a IL-1 $\beta(10 \mathrm{ng} / \mathrm{ml}$; $n=2)$, b MS $(n=19-23)$ or $\mathbf{c}$ T3 $(10 \mathrm{nM} ; n=17)$ as determined by the DMMB assay. Data are represented as
B

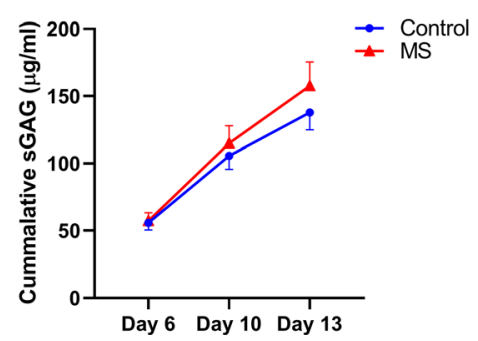

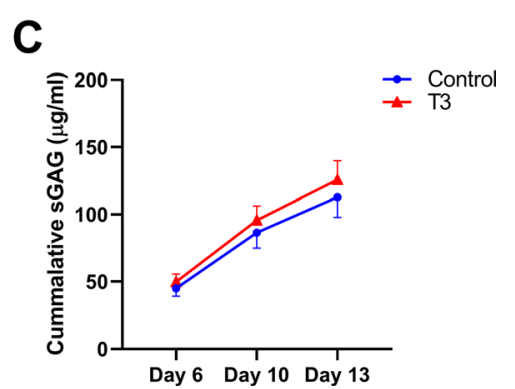

mean \pm SEM. $P$ values of mean differences between controls and treated explants were estimated by generalized estimating equations (GEE) with robust variance estimators to account for donor effects. ${ }^{*} P<0.05$, ${ }^{* *} P<0.01$. SEMs $<0.05$ are not distinguishable in the figure 
A

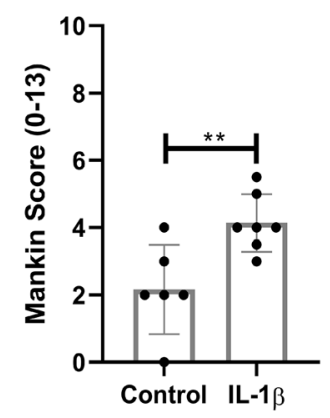

D

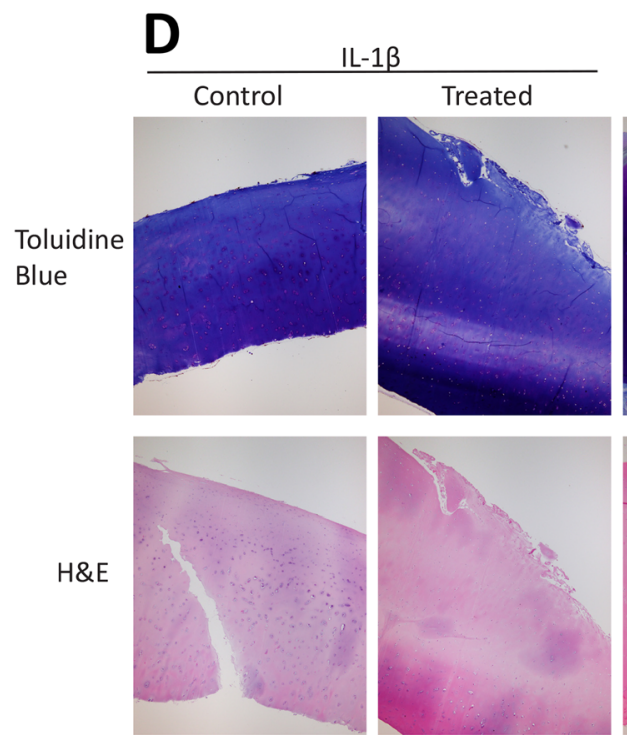

B
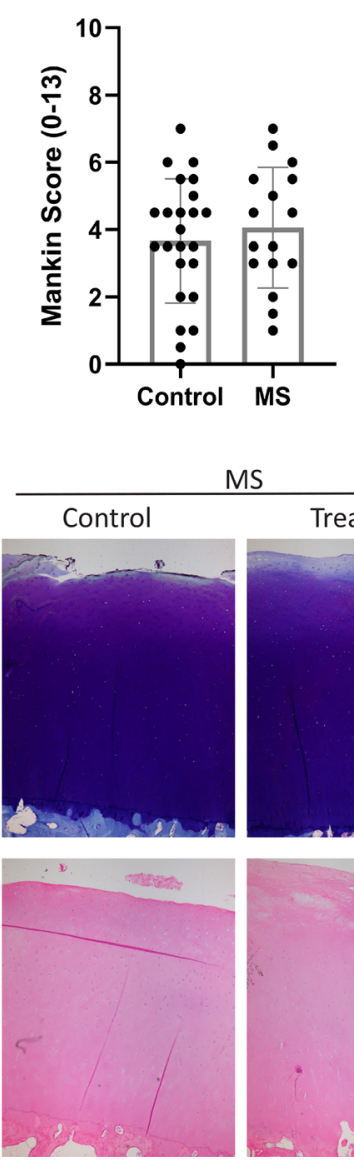

MS

Treated
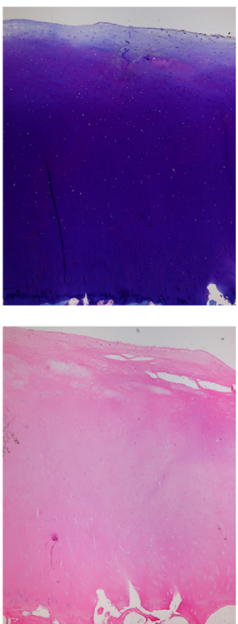

C
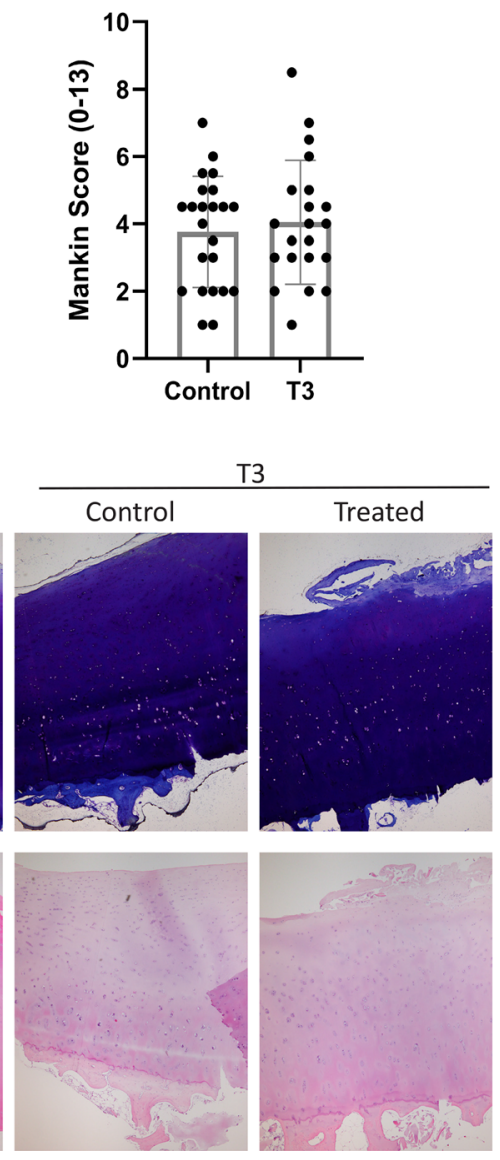

Fig. 5 Mankin score summary and representative histological pictures of cartilage after treatment with IL-1 $\beta$, T3 or $65 \%$ mechanical stress. Cartilage damage was assessed on histology after perturbation with a IL-1 $\beta(n=6)$, b $65 \%$ MS $(n=16 / 24)$ or c T3 $(n=22 / 24)$. Data are represented as mean \pm SEM and each dot represents a single explant. d Representative histological pictures are given of

(Fig. S4C) and 1.7 times increased cartilage surface damage (Fig. S4A). These results of high cartilage breakdown in response to IL-1 $\beta$ are in line with many previous studies, which often observed an increased release of matrix metalloproteinases (MMPs) and other degradative enzymes, production of nitric oxide and inhibition of the synthesis of matrix proteins $[17,30]$. This model might be most suitable to study interventions aimed at a subgroup of OA patients that have more inflammatory toluidine blue and $\mathrm{H} \& \mathrm{E}$ stainings performed on slides from the different conditions. $P$ values of mean differences between controls and treated explants were estimated by generalized estimating equations (GEE) with robust variance estimators to account for donor effects. ${ }^{*} P<0.05,{ }^{* *} P<0.01$

characteristics and might even suffer from rheumatic arthritis.

The perturbation with $65 \%$ MS can be considered a posttraumatic model, triggering modest OA-related changes particularly via catabolism, as reflected by the consistent yet particular effect on MMP13 and EPAS1 (FC= 1.8; $\quad P=1.8 \times 10^{-20} \quad$ and $\quad F C=10.3$; $P=1.4 \times 10^{-2}$, respectively). In addition, we showed a slight decrease in cartilage anabolism as measured by reduced COL $2 A 1$ gene expression $\left(\mathrm{FC}=0.9 ; P=8.7 \times 10^{-2}\right)$. At the protein 
A

B
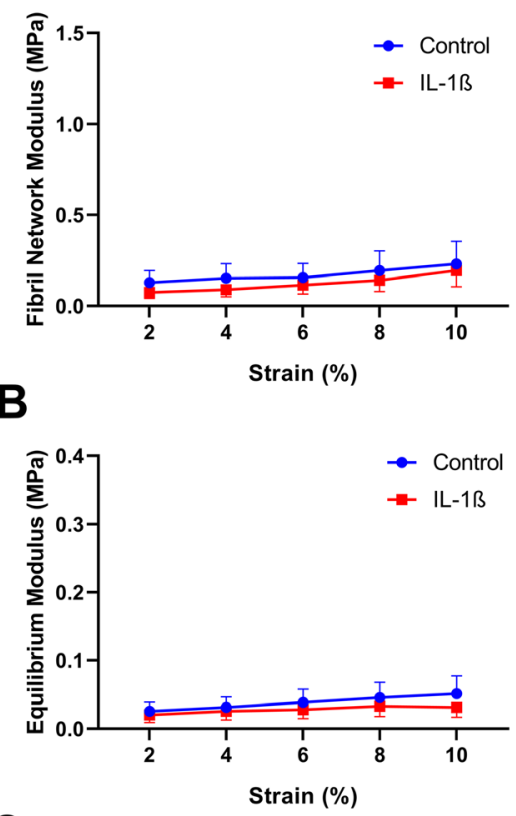

C

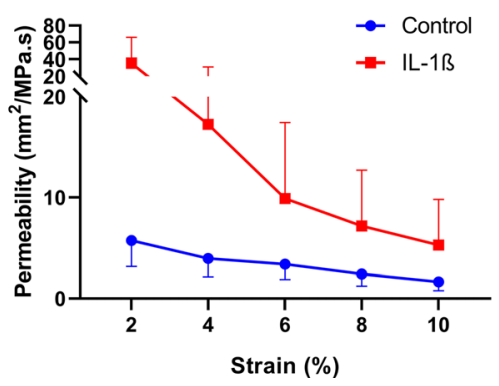

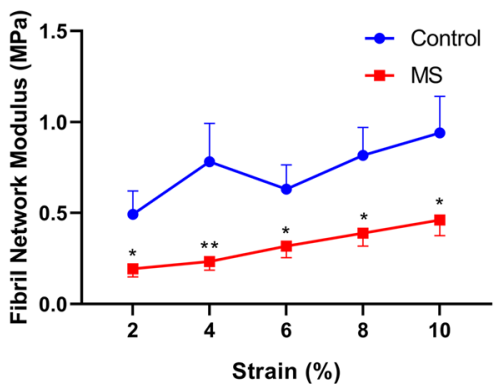
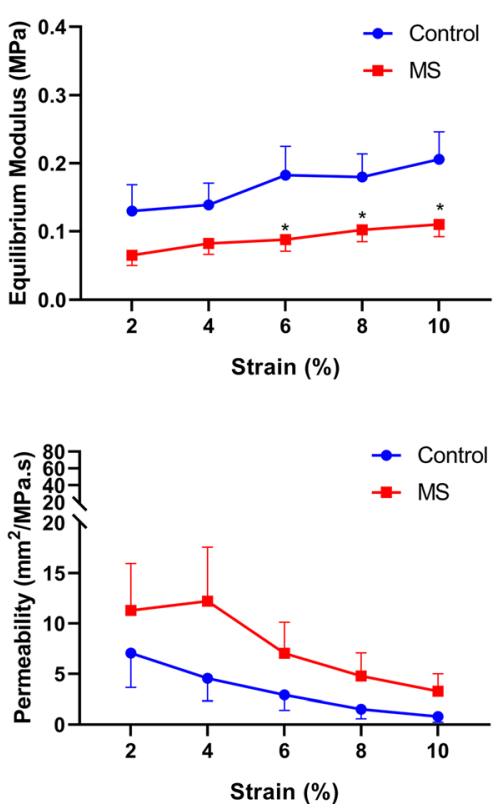
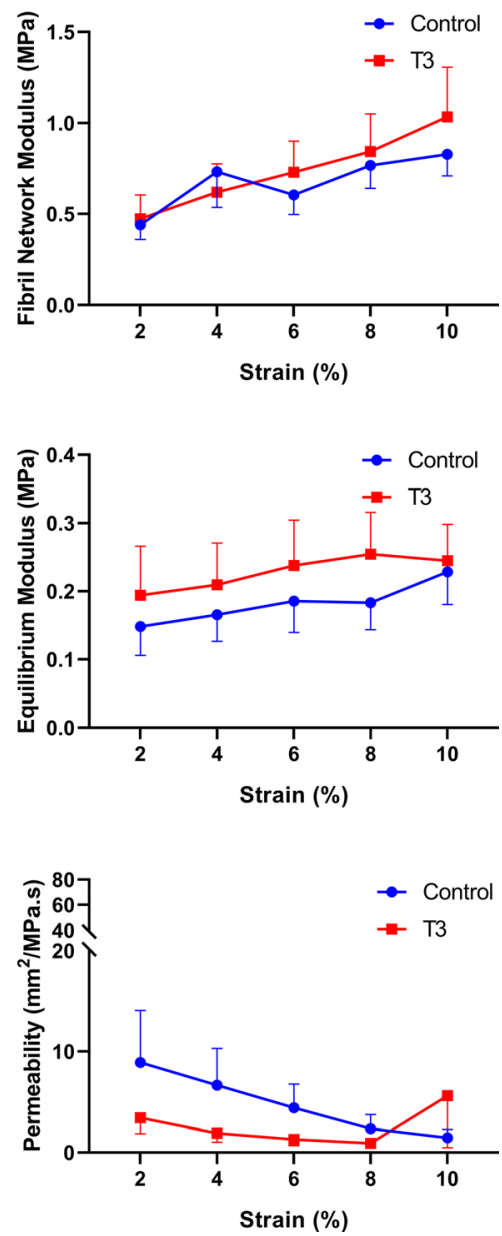

Fig. 6 Mechanical properties of cartilage of osteochondral explants on day 10. Mechanical properties of cartilage were determined after perturbation with IL-1 $\beta(n=3), 65 \%$ MS $(n=19 / 21)$ or T3 $(n=19 / 23)$ using the fibrilnetwork-reinforced biphasic model to calculate the a fibril network modulus, b Young's modulus and c hydraulic

level we measured a $30 \%$ increase of sGAG released from cartilage (Fig. 4c) after 65\% MS, corresponding to the measured slightly higher scoring for sGAG loss in toluidine blue staining (Fig. S4C). Macroscopically, we observed more macrocracks on the cartilage surface (Fig. S5) of explants receiving 65\% MS and this damage was reflected in a substantial unbeneficial change of mechanical properties of the cartilage (Fig. 6). Compared to controls, explants receiving 65\% MS had a 48\% reduced tensile stiffness (Fig. 6a), $55 \%$ reduced Young's modulus (Fig. 6b) and permeability. Data are represented as mean \pm SEM. $P$ values of mean differences between controls and treated explants were estimated by generalized estimating equations (GEE) with robust variance estimators to account for donor effects. ${ }^{*} P<0.05,{ }^{* *} P<0.01$

300\% increased hydraulic permeability (Fig. 6c). These results suggest that the cartilage extracellular matrix is damaged after 65\% MS has been applied as it no longer appears to have the normal elastic properties and water-retaining capabilities that allow cartilage to withstand high loads. We hypothesize that this mechanism of function could be similar to exceeding the injury threshold of mechanical loading during one's life [31]. Exceeding this threshold could occur when the mechanical load is 
suddenly increased or when the joint has lost its natural mechanoprotective properties.

It is generally accepted that biomechanical loading is necessary for the maintenance of cartilage homeostasis, as evidenced by the rapid loss of proteoglycans in joints that are immobilised or in disuse [32]. However, abnormal, altered or injurious loading is associated with inflammatory and metabolic imbalances that may eventually lead to OA-like damage [13, 15, 33-35]. Moreover, ex vivo cartilage explants subjected to these magnitudes of stress exhibit a significant suppression of metabolic activity, and particularly biosynthesis of aggrecan and collagen is affected [13, 15, 33, 34, 36] similar to the in vivo situation [37]. Consistent upregulation of catabolic genes such as RUNX2, MMP1, MMP3, MMP13 and ADAMTS5 has been found in several mechanical injury models using either chondrocytes or cartilage explants $[14,15,38-40]$. The literature has shown that levels of measured genes can vary greatly, depending on the magnitude of force, speed, age of cartilage and at which time point gene expression is measured [41-43]. In our model, we measured targeted genes and in follow-up studies it would be interesting to measure the whole genomic transcript using RNA sequencing to identify different pathways modulating the lasting response to mechanical stress. Our model applying 65\% MS might be most suitable to study interventions aimed at post-traumatic OA patients who would benefit most from a reduction of the (early) response of cartilage to mechanical stress.

In our third model we showed that in response to T3, chondrocyte signalling increased expression of the early hypertrophic markers COL1OA1 and MMP13 $(\mathrm{FC}=5.0$; $P=6.1 \times 10^{-3}$ and $\mathrm{FC}=3.7 ; \quad P=3.0 \times 10^{-3}$, respectively), while also greatly increasing the mineralization markers COL1A1 and ALPL $\left(\mathrm{FC}=144.7 ; \quad P=3.0 \times 10^{-3}\right.$ and $\mathrm{FC}=665.8$; $P=7.4 \times 10^{-9}$, respectively). Together, these results suggest that $\mathrm{T} 3$ induces terminal differentiation towards bone in chondrocytes. Treatment with $\mathrm{T} 3$ also induced a greatly consistent increased gene expression of COL2A1 $(\mathrm{FC}=3.5$; $P=2.4 \times 10^{-10}$ ), but did not affect $A C A N$ expression. Nonetheless, upregulation of
COL2A1 does not necessarily mean that T3 induces a beneficial response of chondrocytes, as COL $2 A 1$ is also upregulated in response to damage. In addition, a microarray study has shown that COL2A1 gene expression is upregulated in preserved compared to healthy cartilage, suggesting that there might be an early role for COL2A1 in the OA process when the cartilage is still trying to repair matrix damage [44]. To understand downstream transcriptional effects of T3, we measured RUNX2 and EPAS1, two critical transcription factors hallmarking $\mathrm{OA}$ and acting downstream of T3. We measured an upregulation of both EPAS1 and RUNX2 $\left(\mathrm{FC}=1.8 ; \quad P=1.0 \times 10^{-3} \quad\right.$ and $\quad \mathrm{FC}=1.2$; $P=7.1 \times 10^{-2}$, respectively), suggesting a possible role for both transcription factors as downstream targets of T3. The changes in chondrocyte signalling after $\mathrm{T} 3$ perturbation did not lead to significant changes of cartilage matrix integrity. Our results indicate that hypertrophy was induced by $\mathrm{T} 3$ in our explant model and that this was not necessarily detrimental to the cartilage matrix. T3 can induce changes in chondrocyte signalling directly by binding to specific thyroid responsive elements (TREs) on the DNA whereby it regulates transcription or more indirectly by activating the transcription of another transcriptional regulator such as RUNX2. However, which genes are transcriptionally regulated by $\mathrm{T} 3$ needs to be elucidated and regulation has been shown to be very tissue-specific because of the different levels and isotypes of thyroid hormone receptors present in different cell types. It is possible that T3 is able to induce multiple genes such as MMP13 in cartilage via binding to TREs. For example, in $\operatorname{tr} \beta$ crispant tadpoles, T3 did not induce MMP13 gene expression, suggesting that $\mathrm{T} 3$ acts via $\operatorname{Tr} \beta$ on inducing transcription [45].

Other researchers have seen similar effects using T3 and T4, with T3 being a more potent inducer of collagen production [46, 47]. However, these two studies did not observe an increase in hypertrophic markers such as COL10 and COL1, and this could be due to the cell type and concentration used in their experiments. On the contrary, in an in vitro chondrogenesis model using human bone marrow-derived stem cells (hBMSCs), perturbation with T3 increased 
chondrocyte cell signalling of terminal maturation markers (ALPL, COL1A1) [37]. Overexpression of $\mathrm{DIO} 2$, encoding for the D2 enzyme which converts T4 into T3, in the same model had even more detrimental effects. This explant model perturbated by T3 might be most suitable to studying interventions aimed at investigating mild types of $\mathrm{OA}$ that are more characterized by occurrence of hypertrophy and mineralization of cartilage.

The observation that we did not measure a response of ADAMTS5 in our three models was unexpected. Possible explanations could be that in general expression levels of ADAMTS5 were too low to be accurately assessed or that ADAMTS5 expression was too heterogeneous between patients to lead to concluding results. A more biological explanation could be the temporal and tight regulation of ADAMTS5 gene expression, peaking $10 \mathrm{~h}$ after injury and declining thereafter [42].

A major strength of our models is that they consider aged, yet preserved, human osteochondral explants of a heterogeneous OA patient population. As a result cartilage explants may reflect a reliable biomimetic model, prone to OA onset. Moreover, despite the heterogeneous patient population we present consistent output specific for three different relevant triggers of OA, allowing for development of different treatment modalities. Some weaknesses of the models concern the scalability and dependency of patients undergoing joint replacement surgery. In addition, we only measured changes of the overall cartilage matrix and not changes of specific proteins that make up the articular cartilage, such as collagen type II. Nonetheless, we advocate that focusing clinical development on directly counteracting these specific unbeneficial responses of chondrocytes upon these OA triggers will facilitate further personalized development and testing of desperately needed disease-modifying OA drugs. Our data provide a reference for development of advanced 3D in vitro model systems of cartilage, bone or osteochondral models aiming towards a joint on a chip using the sensitive changes in gene expression. Moreover, our model offers a next step opportunity for in depth molecular exploration with and without perturbations, e.g., by
RNA sequencing in bulk or at the single-cell level.

\section{CONCLUSION}

Our study demonstrates that it is possible to set up personalized human OA disease models reflecting different relevant aspects (inflammation, hypertrophy and mechanical stress) of OA pathophysiology. The different perturbing factors and their variety in downstream effects could facilitate the development of novel targeted treatment modalities reflecting different aspects of the OA pathophysiology. Applying the here presented aged human explant model could result in a paradigm shift for biomedical research and the pharmaceutical industry leading to new ways to identify desperately needed effective drugs for OA.

\section{ACKNOWLEDGEMENTS}

We would like to thank all study participants of the RAAK study. We thank all the members of our group-Alejandro Rodríguez Ruiz, Ritchie Timmermans, Margo Tuerlings, Rodrigo Coutinho de Almeida and Niek Bloks. We also thank Anika Rabelink-Hoogenstraaten, Demiën Broekhuis, Robert van der Wal, Peter van Schie, Shaho Hasan, Maartje Meijer, Daisy Latijnhouwers and Geertje Spierenburg-for assistance in collecting RAAK samples.

Funding. The research leading to these results has received funding from the Dutch Arthritis Society/ReumaNederland (DAF-15-4401) and the Dutch Scientific Research council NWO/ZonMW VICI scheme (91816631/528). The Leiden University Medical Centre has and is supporting the RAAK study. The Rapid Service Fee and the Open Access fee were funded by the Dutch Scientific Research council NWO/ ZonMW VICI scheme (91816631/528).

Authorship. All named authors meet the International Committee of Medical Journal Editors (ICMJE) criteria for authorship for this article, take responsibility for the integrity of 
the work as a whole, and have given their approval for this version to be published.

Authorship Contributions. Study concept and design: Evelyn Houtman, Yolande F.M. Ramos and Ingrid Meulenbelt. Acquisition of material and data: Evelyn Houtman, Marcella van Hoolwerff, Eka H. D. Suchiman, Nico Lakenberg, Enrike van der Linden - van der Zwaag and Rob G.H.H. Nelissen. Data analysis: Evelyn Houtman, Yolande F.M. Ramos and Ingrid Meulenbelt. Preparation of the manuscript: Evelyn Houtman and Ingrid Meulenbelt. Critical reviewing and approval of the manuscript: All authors.

Disclosures. Evelyn Houtman, Marcella van Hoolwerff, Nico Lakenberg, Eka Suchiman, Enrike van der Linden-van der Zwaag, Rob Nelissen, Yolande Ramos and Ingrid Meulenbelt declare that they have nothing to disclose.

Compliance with Ethics Guidelines. The RAAK study has been approved by the medical ethical committee of the Leiden University Medical Center (P08.239/P19.013). Patients provided written informed consent to participate in the study and had the right to withdraw at any time.

Data Availability. The datasets during and/ or analysed during the current study available from the corresponding author on reasonable request.

Open Access. This article is licensed under a Creative Commons Attribution-NonCommercial 4.0 International License, which permits any non-commercial use, sharing, adaptation, distribution and reproduction in any medium or format, as long as you give appropriate credit to the original author(s) and the source, provide a link to the Creative Commons licence, and indicate if changes were made. The images or other third party material in this article are included in the article's Creative Commons licence, unless indicated otherwise in a credit line to the material. If material is not included in the article's Creative Commons licence and your intended use is not permitted by statutory regulation or exceeds the permitted use, you will need to obtain permission directly from the copyright holder. To view a copy of this licence, visit http://creativecommons.org/licenses/by$\mathrm{nc} / 4.0 /$.

\section{REFERENCES}

1. Atkins GJ, Welldon KJ, Halbout P, Findlay DM. Strontium ranelate treatment of human primary osteoblasts promotes an osteocyte-like phenotype while eliciting an osteoprotegerin response. Osteoporos Int. 2009;20(4):653-64.

2. Woolf AD, Erwin J, March L. The need to address the burden of musculoskeletal conditions. Best Pract Res Clin Rheumatol. 2012;26(2):183-224.

3. Dreier R. Hypertrophic differentiation of chondrocytes in osteoarthritis: the developmental aspect of degenerative joint disorders. Arthritis Res Ther. 2010;12(5):216.

4. Pfander D, Swoboda B, Kirsch T. Expression of early and late differentiation markers (proliferating cell nuclear antigen, syndecan-3, annexin VI, and alkaline phosphatase) by human osteoarthritic chondrocytes. Am J Pathol. 2001;159(5):1777-83.

5. von der Mark K, Kirsch T, Nerlich A, Kuss A, Weseloh G, Gluckert K, et al. Type X collagen synthesis in human osteoarthritic cartilage. Indication of chondrocyte hypertrophy. Arthritis Rheum. 1992;35(7):806-11.

6. Poole AR, Nelson F, Dahlberg L, Tchetina E, Kobayashi M, Yasuda T, et al. Proteolysis of the collagen fibril in osteoarthritis. Biochem Soc Symp. 2003;70:115-23.

7. Fuerst M, Bertrand J, Lammers L, Dreier R, Echtermeyer F, Nitschke Y, et al. Calcification of articular cartilage in human osteoarthritis. Arthritis Rheum. 2009;60(9):2694-703.

8. Kuhn K, D'Lima DD, Hashimoto S, Lotz M. Cell death in cartilage. Osteoarthr Cartil. 2004;12(1): $1-16$.

9. Goldring MB, Goldring SR. Articular cartilage and subchondral bone in the pathogenesis of osteoarthritis. Ann N Y Acad Sci. 2010;1192:230-7.

10. Bird JL, Wells T, Platt D, Bayliss MT. IL-1 beta induces the degradation of equine articular cartilage by a mechanism that is not mediated by nitric 
oxide. Biochem Biophys Res Commun. 1997;238(1):81-5.

11. Clutterbuck AL, Mobasheri A, Shakibaei M, Allaway D, Harris P. Interleukin-1beta-induced extracellular matrix degradation and glycosaminoglycan release is inhibited by curcumin in an explant model of cartilage inflammation. Ann N Y Acad Sci. 2009;1171:428-35.

12. Geurts J, Jurić D, Müller M, Schären S, Netzer C. Novel ex vivo human osteochondral explant model of knee and spine osteoarthritis enables assessment of inflammatory and drug treatment responses. Int J Mol Sci. 2018;19(5):1314.

13. Kurz B, Jin M, Patwari P, Cheng DM, Lark MW, Grodzinsky AJ. Biosynthetic response and mechanical properties of articular cartilage after injurious compression. J Orthop Res. 2001;19(6): 1140-6.

14. Chan PS, Schlueter AE, Coussens PM, Rosa GJ, Haut RC, Orth MW. Gene expression profile of mechanically impacted bovine articular cartilage explants. J Orthop Res. 2005;23(5):1146-51.

15. Quinn TM, Grodzinsky AJ, Hunziker EB, Sandy JD. Effects of injurious compression on matrix turnover around individual cells in calf articular cartilage explants. J Orthop Res. 1998;16(4):490-9.

16. Bomer N, den Hollander W, Ramos YF, Meulenbelt I. Translating genomics into mechanisms of disease: osteoarthritis. Best Pract Res Clin Rheumatol. 2015;29(6):683-91.

17. Lv M, Zhou Y, Polson SW, Wan LQ, Wang M, Han $\mathrm{L}$, et al. Identification of chondrocyte genes and signaling pathways in response to acute joint inflammation. Sci Rep. 2019;9(1):93.

18. Vincent TL. IL-1 in osteoarthritis: time for a critical review of the literature. F1000Res. 2019;8.

19. Mackay AM, Beck SC, Murphy JM, Barry FP, Chichester CO, Pittenger MF. Chondrogenic differentiation of cultured human mesenchymal stem cells from marrow. Tissue Eng. 1998;4(4):415-28.

20. Mueller MB, Tuan RS. Functional characterization of hypertrophy in chondrogenesis of human mesenchymal stem cells. Arthritis Rheum. 2008;58(5): 1377-88.

21. Sanchez-Adams J, Leddy HA, McNulty AL, O'Conor CJ, Guilak F. The mechanobiology of articular cartilage: bearing the burden of osteoarthritis. Curr Rheumatol Rep. 2014;16(10):451.

22. Farndale RW, Buttle DJ, Barrett AJ. Improved quantitation and discrimination of sulphated glycosaminoglycans by use of dimethylmethylene blue. Biochim Biophys Acta. 1986;883(2):173-7.

23. Mankin HJ, Dorfman H, Lippiello L, Zarins A. Biochemical and metabolic abnormalities in articular cartilage from osteo-arthritic human hips. II. Correlation of morphology with biochemical and metabolic data. J Bone Jt Surg Am. 1971;53(3): 523-37.

24. Soulhat J, Buschmann MD, Shirazi-Adl A. A fibrilnetwork-reinforced biphasic model of cartilage in unconfined compression. J Biomech Eng. 1999;121(3):340-7.

25. McCulloch RS, Ashwell MS, O'Nan AT, Mente PL. Identification of stable normalization genes for quantitative real-time PCR in porcine articular cartilage. J Anim Sci Biotechnol. 2012;3(1):36.

26. Al-Sabah A, Stadnik P, Gilbert SJ, Duance VC, Blain EJ. Importance of reference gene selection for articular cartilage mechanobiology studies. Osteoarthr Cartil. 2016;24(4):719-30.

27. Saito T, Fukai A, Mabuchi A, Ikeda T, Yano F, Ohba $S$, et al. Transcriptional regulation of endochondral ossification by HIF-2alpha during skeletal growth and osteoarthritis development. Nat Med. 2010;16(6):678-86.

28. Yang S, Kim J, Ryu JH, Oh $\mathrm{H}$, Chun $\mathrm{CH}$, Kim BJ, et al. Hypoxia-inducible factor-2alpha is a catabolic regulator of osteoarthritic cartilage destruction. Nat Med. 2010;16(6):687-93.

29. Bohensky J, Terkhorn SP, Freeman TA, Adams CS, Garcia JA, Shapiro IM, et al. Regulation of autophagy in human and murine cartilage: hypoxia-inducible factor 2 suppresses chondrocyte autophagy. Arthritis Rheum. 2009;60(5):1406-15.

30. Pelletier JP, Mineau F, Ranger P, Tardif G, MartelPelletier J. The increased synthesis of inducible nitric oxide inhibits IL-1ra synthesis by human articular chondrocytes: possible role in osteoarthritic cartilage degradation. Osteoarthr Cartil. 1996;4(1):77-84.

31. Vincent TL, Wann AKT. Mechanoadaptation: articular cartilage through thick and thin. J Physiol. 2019;597(5):1271-81.

32. Sun HB. Mechanical loading, cartilage degradation, and arthritis. Ann N Y Acad Sci. 2010;1211:37-50.

33. Patwari P, Cook MN, DiMicco MA, Blake SM, James IE, Kumar S, et al. Proteoglycan degradation after injurious compression of bovine and human articular cartilage in vitro: interaction with exogenous cytokines. Arthritis Rheum. 2003;48(5):1292-301. 
34. Patwari P, Cheng DM, Cole AA, Kuettner KE, Grodzinsky AJ. Analysis of the relationship between peak stress and proteoglycan loss following injurious compression of human post-mortem knee and ankle cartilage. Biomech Model Mechanobiol. 2007;6(1-2):83-9.

35. Guilak F. Biomechanical factors in osteoarthritis. Best Pract Res Clin Rheumatol. 2011;25(6):815-23.

36. Guilak F, Meyer BC, Ratcliffe A, Mow VC. The effects of matrix compression on proteoglycan metabolism in articular cartilage explants. Osteoarthr Cartil. 1994;2(2):91-101.

37. Bomer $\mathrm{N}$, den Hollander $\mathrm{W}$, Ramos YF, Bos SD, van der Breggen R, Lakenberg $\mathrm{N}$, et al. Underlying molecular mechanisms of DIO2 susceptibility in symptomatic osteoarthritis. Ann Rheum Dis. 2015;74(8):1571-9.

38. Riegger J, Joos H, Palm HG, Friemert B, Reichel H, Ignatius $\mathrm{A}$, et al. Antioxidative therapy in an ex vivo human cartilage trauma-model: attenuation of trauma-induced cell loss and ECM-destructive enzymes by $\mathrm{N}$-acetyl cysteine. Osteoarthr Cartil. 2016;24(12):2171-80.

39. Tetsunaga T, Nishida K, Furumatsu T, Naruse K, Hirohata S, Yoshida A, et al. Regulation of mechanical stress-induced MMP-13 and ADAMTS-5 expression by RUNX-2 transcriptional factor in SW1353 chondrocyte-like cells. Osteoarthr Cartil. 2011;19(2):222-32.

40. Ashwell MS, Gonda MG, Gray K, Maltecca C, O'Nan AT, Cassady JP, et al. Changes in chondrocyte gene expression following in vitro impaction of porcine articular cartilage in an impact injury model. J Orthop Res. 2013;31(3):385-91.

41. Madej W, van Caam A, Blaney Davidson EN, van der Kraan PM, Buma P. Physiological and excessive mechanical compression of articular cartilage activates Smad2/3P signaling. Osteoarthr Cartil. 2014;22(7):1018-25.

42. Lee JH, Fitzgerald JB, Dimicco MA, Grodzinsky AJ. Mechanical injury of cartilage explants causes specific time-dependent changes in chondrocyte gene expression. Arthritis Rheum. 2005;52(8): 2386-95.

43. Fitzgerald JB, Jin M, Dean D, Wood DJ, Zheng MH, Grodzinsky AJ. Mechanical compression of cartilage explants induces multiple time-dependent gene expression patterns and involves intracellular calcium and cyclic AMP. J Biol Chem. 2004;279(19): 19502-11.

44. Ramos YF, den Hollander W, Bovee JV, Bomer N, van der Breggen $\mathrm{R}$, Lakenberg $\mathrm{N}$, et al. Genes involved in the osteoarthritis process identified through genome wide expression analysis in articular cartilage; the RAAK study. PLoS ONE. 2014;9(7):e103056.

45. Sakane Y, Iida M, Hasebe T, Fujii S, Buchholz DR, Ishizuya-Oka A, et al. Functional analysis of thyroid hormone receptor beta in Xenopus tropicalis founders using CRISPR-Cas. Biol Open. 2018. https:// doi.org/10.1242/bio.030338.

46. Whitney GA, Kean TJ, Fernandes RJ, Waldman S, Tse MY, Pang SC, et al. Thyroxine increases collagen type II expression and accumulation in scaffold-free tissue-engineered articular cartilage. Tissue Eng Part A. 2018;24(5-6):369-81.

47. Glade MJ, Kanwar YS, Stern PH. Insulin and thyroid hormones stimulate matrix metabolism in primary cultures of articular chondrocytes from young rabbits independently and in combination. Connect Tissue Res. 1994;31(1):37-44. 